Iranian Journal of Pathology | ISSN: 2345-3656

\title{
Evaluation of ERG Expression in Prostate Adenocarcinoma and Its Prognostic Impact in Patients Survival Rate
}

\author{
Hedieh Moradi Tabriz' (iD), Leila Aghapour Sabaghi' ${ }^{1}$, Amirreza Nabighadim², \\ Elham Nazar ${ }^{1}$, Seyed Mohammad Kazem Aghamir ${ }^{3 *}$
}

1. Department of Pathology, Sina Hospital, Tehran University of Medical Sciences, Tehran, Iran

2. Pediatric Urology and Regenerative Medicine Research Center, Children's Medical Center, Tehran University of Medical Sciences, Tehran, Iran

3. Urology Research Center, Tehran University of Medical Sciences, Tehran, Iran

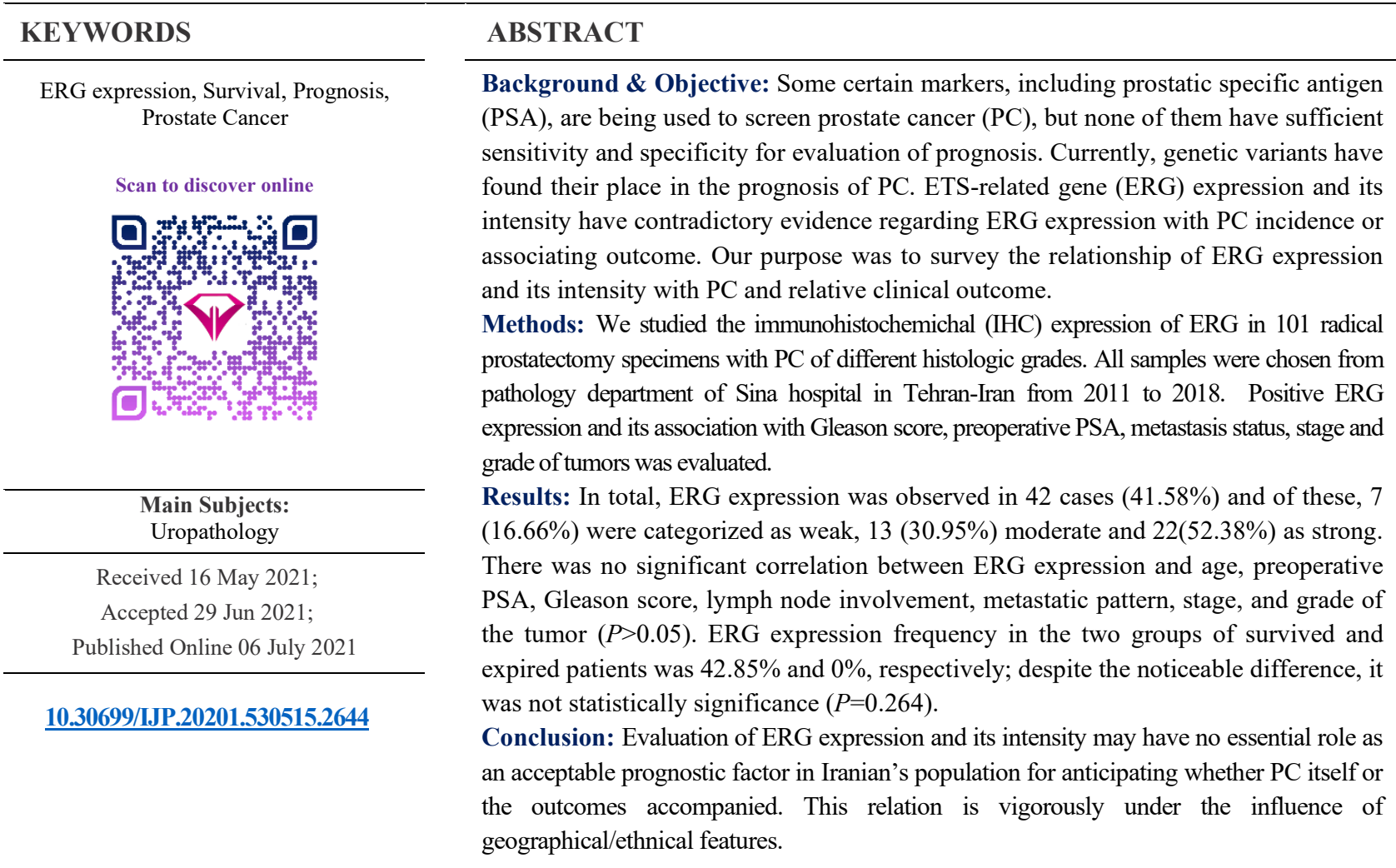
\begin{tabular}{ll}
\hline Corresponding Information: & $\begin{array}{l}\text { Seyed Mohammad Kazem Aghamir Urology Research Center, Tehran University of Medical Sciences, Tehran, } \\
\text { Iran E-mail: mkaghamir@tums.ac.ir }\end{array}$
\end{tabular}

Copyright (C) 2021. This is an open-access article distributed under the terms of the Creative Commons Attribution- 4.0 International License which permits Share, copy and redistribution of the material in any medium or format or adapt, remix, transform, and build upon the material for any purpose, even commercially.

\section{Introduction}

Prostate adenocarcinoma is known as the second predominant cancer in the male population of developed countries like United States (1), with a widely higher prevalence among western communities (2). Approximately more than 240 thousand of new cases are diagnosed annually (3), including $16 \%$ of all men with the age of 67 years and older. The mortality rate of Prostate Cancer (PC) in the US was almost 30 thousand in 2012, occupying the second place between the cancers after lung cancer (4). Nowadays, some various chemical markers, including prostatic specific antigen (PSA), are being used to screen PC; however, none of these markers have sufficient sensitivity and specificity for prognosis evaluation $(5,6)$. So, it is essential to discover the factors, which play an important role affecting PSA level. Studies showed that prostatitis can increase PSA level. The age of these patients is usually high and might need colonoscopy for other reason which colonoscopy can increase the PSA level. So, it is required to question for a colonoscopy before measuring PSA (7). But, cystoscopy has no effect on PSA level and does not lead to its elevation (8). Despite the widespread application of PSA in the screening of PC, this neoplasia continues to immolate a huge number of victims; furthermore, its value in the early and seasonable prognosis of cancer has been cast doubt on (6). The high mortality rate of PC mainly is due to disease relapse and also progression to a metastatic disease; hence, detection of markers and specific methods for diagnosis and even treatment follow-up remains a necessity $(9,10)$. In this regard and for the first time in 2005, ERG (ETS-related gene) was 
introduced as a particular proto-oncogene for PC and has been demonstrated increased expression in more than $72 \%$ of PC cases (11). ERG, a member of the ETS (erythroblast transformation-specific) family, located on Chromosome 21, serves as a transcription regulator, which innately plays a considerable role in embryonic development, cell proliferation, differentiation, angiogenesis, inflammation, and apoptosis $(12,13)$.

In the preliminary studies, ERG or ETS related products have been showed to be fundamental in hematopoiesis, hematopoietic stem cells normal function and also maintaining the platelet regular function and count (14). Additionally, ERG expression has been investigated in $\mathrm{PC}$; the most common genetic alteration is the fusion of $5^{\prime}$ non-coding region of TMPRSS2 gene with one of the ETS family members; ERG involves in more than $90 \%$ of these fusions so can be tracked by immunohistochemistry (IHC) $(15,16)$. TMPRSS2 in prostate tissue associates with decreased expression and function of androgens (6). In the cultured prostate cancerous cells, androgen dependent ERG up-regulation in the Vertebral-Cancer of the Prostate (VCaP) androgen-sensitive cell lines has been detected (17). Overall, based on accomplished studies, TMPR-SS2-ERG fusion isoforms have been propounded as the PC progression mediator (18). It should be noted that there is a crucial difference in PC prevalence amongst western and eastern countries (19). PC incidence in western communities is 20 times higher than in eastern states. Additionally, prior studies demonstrated that TMPRSS2 and ERG fusion in the east, unlike the west, had far less frequency $(21 \%$ in Korea and $28 \%$ in Japan, in comparison to 42 to $60 \%$ in USA) (20). These variants and geographical/ethnical differences are possibly linked to distinction in various molecular mechanisms in prostate tumorigenesis in the noted countries.

There are two important questions coming in the mind we would like to know; first about the frequency of positivity of this marker in astern societies as well as the diagnostic value in the early stages of PC; and second, to to detect any association between expression of this indicator and the consequences of disease such as mortality and survival rate in long term. Therefore, the present study initially evaluated the ERG expression in a selected group of Iranian's population; then the prognostic value of the obtained data in the survival rate prediction was examined.

\section{Material and Methods}

\section{Patients}

In the current retrospective cohort study, we included 101 patients with PC which had undergone radical prostatectomy between 2011 and 2018. All the patients were selected from electronic registry of Department of Pathology, Sina hospital affiliated to
Tehran University of Medical Sciences. Sample size was calculated using Formula 1 with confidence level $95 \%$ and $\alpha$ is 0.05 .

$$
x=\frac{\mathrm{P} *(1-\mathrm{P}) * \mathrm{Z}^{2} 1-\alpha / 2}{\mathrm{~d}^{2}} \quad \text { Formula } 1
$$

The following data including demographic information, pre-operation PSA, Gleason score, the extent of tumor invasion, tumor's grade and stage, lymph node involvement, distant metastasis, and formalin-fixed paraffin-embedded primary tumor samples for IHC analysis were considered as requirements for enrollment of each patient. The duration of follow-up was calculated from the date of surgery to the date of death or 12 months. So, all the patients were evaluated after 12 months from surgery for recurrence or distant metastasis. Cases with incomplete information were excluded. The study protocol was approved by the Ethics Committee of Tehran University of Medical Sciences (ethical code: IR. TUMS.MEDICINE.REC.1398.004).

\section{ERG Expression}

For Immunohistochemical staining to evaluate the ERG gene expression (mouse monoclonal, Biocare Medical company, clone 9FY), 3 microns' sections were obtained from every patient's appropriate paraffin block in the pathology ward. Each section was placed 20 minutes at $58^{\circ} \mathrm{C}$. Afterward, the sections were deparaffinized and rehydrated by the aid of xylene bath and graded alcohol series. Phosphate buffer was added to peroxidase inactivation. Slides were then incubated with the primary antibody at room temperature for one hour. After washing with PBS, secondary antibody was added, which was washed after 30-40 minutes. Slides were counterstained with hematoxylin. ERG protein has a nuclear expression and on the other hand, its cytoplasmicdiffusion is weak. The prepared slides were observed and examined by two pathologists and IHC results were categorized into four groups, including negative $(-)$, weak $(1+)$, moderate $(2+)$ and strong $(3+)$. Similarly, ERG gene expression was assessed in non-tum-oral tissues, too (Figure 1). Endothelial cells of small vessels and the lymphocytes serve as positive internal controls (21).

\section{Statistical Analyses}

Parametric data were presented as mean and standard deviation (mean \pm SD) and nonparametric ordinal data were presented as frequency and relative frequency. T-test and Chi-square test were performed on quantitative and qualitative data, respectively. ERG prognostic value in predicting patients' survival and the mortality rate were determined by a Cox proportional hazards test and the Kaplan-Meier method. The Pvalue less than 0.05 was considered statistically significant. For statistical analyses of the data, SPSS software version 21 (SPSS Inc., Chicago, Ill., USA) was used. 


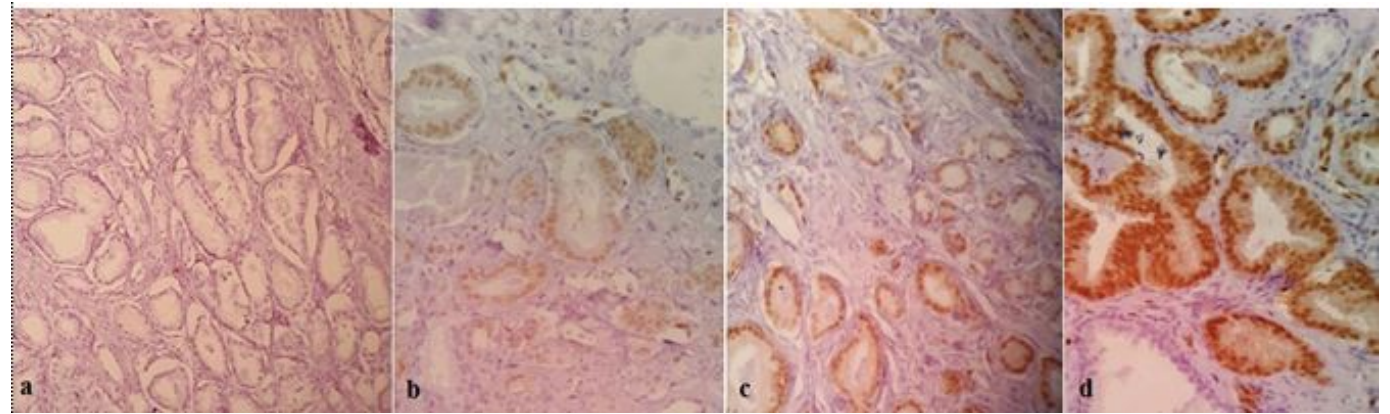

Fig. 1. Different ERG expression intensity. a: negative expression; b: weak expression; c: moderate expression; d: strong expression.

\section{Results}

\section{Basic Information}

Among 101 prostate cancer patients enrolled in this study, the average age was $64.81 \pm 7.11$ ranging from 51 to 81 . As illustrated in Table 1, the mean Gleason score was $7.57 \pm 1.34$. Regarding the pathologic tumor stage, PT1a in $2(1.98 \%)$, PT1b in $1(0.99 \%)$, PT2a in 17 (16.83\%), РT2b in $10(9.9 \%)$, РT2c in $43(42.57 \%)$, PT3a in 6 (5.94\%), PT3b in $20(19.8 \%)$ and PT3c was reported in $2(1.98 \%)$ of cases. Lymphatic involvement and distant metastases were present in $5(4.95 \%)$ and 7 (6.93\%) samples, respectively. Of 101 specimens, 25
$(24.75 \%)$ took place in in grade group 1, $40(39.6 \%)$ in grade group 2, 16 (15.84\%) in grade group 3, $4(3.96 \%)$ in grade group 4 and $16(15.84 \%)$ grade group 5 . The mean amount of primary preoperative PSA was $15.77 \pm 13.5$. In terms of cancer-related mortality status during the performed follow-up, $3(2.97 \%)$ of the patients passed away; but, the cause of death was perioperative problems in the first case, comorbid esophageal cancer for the second one and in the third patient was indeterminate. The overall survival rate was $97 \%$.

Table 1. Primary characteristics of the patients with prostate cancer

\begin{tabular}{|c|c|c|c|c|}
\hline & Mean \pm SD & Frequency & Relative Frequency \\
\hline Age & & $64.81 \pm 7.11$ & --- & -- \\
\hline \multicolumn{2}{|c|}{ Gleason score } & $7.57 \pm 1.34$ & --- & -- \\
\hline \multicolumn{2}{|c|}{ Primary PSA Level } & $15.77 \pm 13.5$ & --- & -- \\
\hline \multirow{9}{*}{ 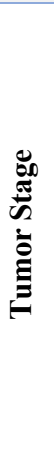 } & PT1a & -- & 2 & $1.98 \%$ \\
\hline & PT1b & --- & 1 & $0.99 \%$ \\
\hline & PT2a & --- & 17 & $16.83 \%$ \\
\hline & PT2b & --- & 10 & $9.90 \%$ \\
\hline & PT2c & --- & 43 & $42.57 \%$ \\
\hline & PT3a & --- & 6 & $5.94 \%$ \\
\hline & PT3b & --- & 20 & $19.80 \%$ \\
\hline & PT3c & --- & 2 & $1.98 \%$ \\
\hline & Total & --- & 101 & $100 \%$ \\
\hline \multicolumn{2}{|c|}{ Lymph node involvement } & --- & 5 & $4.95 \%$ \\
\hline \multicolumn{2}{|c|}{ Metastasis } & --- & 7 & $6.93 \%$ \\
\hline \multirow{6}{*}{ 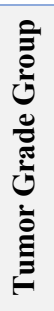 } & 1 & --- & 25 & $24.75 \%$ \\
\hline & 2 & --- & 40 & $39.60 \%$ \\
\hline & 3 & --- & 16 & $15.84 \%$ \\
\hline & 4 & --- & 4 & $3.96 \%$ \\
\hline & 5 & --- & 16 & $15.84 \%$ \\
\hline & Total & --- & 101 & $100 \%$ \\
\hline
\end{tabular}

ERG Expression Depending on Primary Specificities and Disease Outcome

We identified a total of 42 cases $(41.58 \%)$ of ERG expressed samples; $7(16.66 \%)$ out of those were classified as weak expression while $13(30.95 \%)$ and $22(52.38 \%)$ were as moderate and strong, respectively. . Patients' average age and mean Gleason score in positive and negative expression group were 
$64.24 \pm 7.71,65.22 \pm 6.69$, and $7.88 \pm 1.89,7.36 \pm 1.74$, respectively; according to the given data, there was no significant relation between ERG expression and age, mean and every state of Gleason score $(P=0.497$, $P=0.152$ and $P=0.211$ ).

The frequency of ERG expression in different tumor grades and stages are displayed in Table 2 in which no significant differences in expression rate were seen in any of the grades and stages of tumors ( $P=0.066$ and $P=0.462)$. ERG expression was observed in $40 \%$ of all lymph node positive samples and in $41.66 \%$ of negative lymph nodes specimens; however, no significant correlation was detected $(P=0.926)$.

ERG expression was seen in $42.85 \%$ of metastatic and $41.48 \%$ of non-metastatic cases, indicating no considerable difference $(P=0.944)$. According to the data provided in Table 2, average PSA level and ERG expression were not statistically correlated $(P=0.964)$. Despite the phenomenal difference of ERG expression in two groups of expired and survived patients, there was no remarkable statistical association $(P=0.264)$.
ERG Expression Intensity Depending on Primary Specificities and Disease Outcome

All the data concerning primary specificities and disease outcome corresponding to ERG expression intensity was provided in Table 3 and also comparisons addressing in this section was among these three groups. Regarding the close numbers of mean ages and Gleason score in aforementioned groups, no considerable affinity was established $(P=0.696$ and $P=0.493)$. Referring to the given percentages in Table $\underline{3}$, we were incapable of finding a notable relation between different tumor stages and grades and ERG expression intensity $(P=0.402$ and $P=0.547)$. Similarly, the same thing was verified for the lymph node involvement $(P=0.385)$, metastasis status $(0.168)$ and mean PSA level $(P=0.329)$. Eventually, as ERG had no expression in expired patients, evaluating the expression intensity association with mortality was not feasible.

Table 2. ERG expression depending on primary characteristics

\begin{tabular}{|c|c|c|c|c|c|c|c|c|}
\hline & & \multicolumn{2}{|c|}{ Mean \pm SD } & \multicolumn{2}{|c|}{ Frequency } & \multicolumn{2}{|c|}{ Relative Frequency } & \multirow{2}{*}{ P-value } \\
\hline & & $\begin{array}{c}+ \text { ERG } \\
\text { expression }\end{array}$ & $\begin{array}{c}\text { - ERG } \\
\text { expression }\end{array}$ & $\begin{array}{c}+ \text { ERG } \\
\text { expression }\end{array}$ & $\begin{array}{c}\text { - ERG } \\
\text { expression }\end{array}$ & $\begin{array}{c}+ \text { ERG } \\
\text { expression }\end{array}$ & $\begin{array}{c}\text { - ERG } \\
\text { expression }\end{array}$ & \\
\hline \multicolumn{2}{|c|}{ Age } & $64.24 \pm 7.71$ & $65.22 \pm 6.69$ & --- & --- & --- & --- & 0.497 \\
\hline \multicolumn{2}{|c|}{ Gleason score } & $7.88 \pm 1.89$ & $7.36 \pm 1.74$ & --- & --- & --- & --- & 0.152 \\
\hline \multicolumn{2}{|c|}{ Primary PSA } & $15.70 \pm 13.22$ & $15.83 \pm 13.84$ & --- & --- & --- & --- & 0.964 \\
\hline \multirow{9}{*}{ 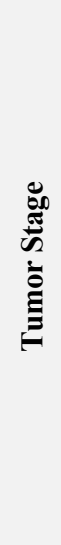 } & PT1a & --- & --- & 0 & 2 & 0 & $3.38 \%$ & \multirow{9}{*}{ 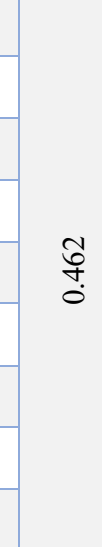 } \\
\hline & PT1b & --- & --- & 0 & 1 & 0 & $1.69 \%$ & \\
\hline & PT2a & --- & --- & 5 & 12 & $11.9 \%$ & $20.33 \%$ & \\
\hline & PT2b & --- & --- & 4 & 6 & $9.52 \%$ & $10.16 \%$ & \\
\hline & PT2c & --- & --- & 20 & 23 & $47.61 \%$ & $38.98 \%$ & \\
\hline & PT3a & --- & --- & 2 & 4 & $4.76 \%$ & $6.77 \%$ & \\
\hline & PT3b & --- & --- & 9 & 11 & $21.42 \%$ & $18.64 \%$ & \\
\hline & PT3c & --- & --- & 2 & 0 & $4.76 \%$ & 0 & \\
\hline & Total & --- & --- & 42 & 59 & $100 \%$ & $100 \%$ & \\
\hline \multicolumn{2}{|c|}{$\begin{array}{l}\text { Lymph node } \\
\text { involvement }\end{array}$} & --- & --- & 2 & 3 & $4.76 \%$ & $5.08 \%$ & 0.926 \\
\hline \multicolumn{2}{|c|}{$\begin{array}{c}\text { Distant } \\
\text { Metastasis }\end{array}$} & --- & --- & 3 & 4 & $7.14 \%$ & $6.77 \%$ & 0.944 \\
\hline \multirow{6}{*}{ 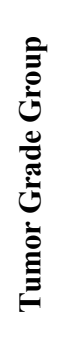 } & 1 & --- & --- & 6 & 19 & $14.28 \%$ & $32.2 \%$ & \multirow{6}{*}{$\stackrel{8}{\circ}$} \\
\hline & 2 & --- & --- & 22 & 18 & $52.38 \%$ & $30.5 \%$ & \\
\hline & 3 & --- & --- & 6 & 10 & $14.28 \%$ & $16.94 \%$ & \\
\hline & 4 & --- & --- & 3 & 1 & $7.14 \%$ & $1.69 \%$ & \\
\hline & 5 & --- & --- & 5 & 11 & $11.9 \%$ & $18.64 \%$ & \\
\hline & Total & --- & --- & 42 & 59 & $100 \%$ & $100 \%$ & \\
\hline
\end{tabular}


*T-test and Chi-square test were performed on quantitative and qualitative data, respectively. Mortality was evaluated by Cox proportional Hazard test.

Table 3. ERG expression intensity depending on primary characteristics

\begin{tabular}{|c|c|c|c|c|c|c|c|c|c|c|c|}
\hline & \multicolumn{3}{|c|}{ Mean \pm SD } & \multicolumn{3}{|c|}{ Frequency } & \multicolumn{3}{|c|}{ Relative Frequency } & \multirow[b]{2}{*}{$\begin{array}{c}\text { P- } \\
\text { valu } \\
\text { e }\end{array}$} \\
\hline & & $\begin{array}{c}\text { Weak } \\
\text { expressio } \\
n\end{array}$ & $\begin{array}{c}\text { Moderate } \\
\text { expressio } \\
\mathbf{n}\end{array}$ & $\begin{array}{c}\text { Strong } \\
\text { expression }\end{array}$ & $\begin{array}{c}\text { Weak } \\
\text { expressio } \\
\mathbf{n}\end{array}$ & $\begin{array}{l}\text { Moderat } \\
\text { e } \\
\text { expressio } \\
\text { n }\end{array}$ & $\begin{array}{c}\text { Strong } \\
\text { expressio } \\
n\end{array}$ & $\begin{array}{c}\text { Weak } \\
\text { expressio } \\
n\end{array}$ & $\begin{array}{l}\text { Moderat } \\
\text { e } \\
\text { expressio } \\
\mathbf{n}\end{array}$ & $\begin{array}{c}\text { Strong } \\
\text { expressio } \\
n\end{array}$ & \\
\hline \multicolumn{2}{|c|}{ Age } & $\begin{array}{c}63.29 \pm 6.9 \\
6\end{array}$ & $\begin{array}{c}65.77 \pm 8.2 \\
5\end{array}$ & $63.64 \pm 7.82$ & --- & --- & --- & --- & --- & --- & $\begin{array}{c}0.69 \\
6\end{array}$ \\
\hline \multicolumn{2}{|c|}{$\begin{array}{c}\text { Gleason } \\
\text { score }\end{array}$} & $8.29 \pm 2.56$ & $8.23 \pm 1.88$ & $7.55 \pm 1.68$ & --- & --- & --- & --- & --- & --- & $\begin{array}{c}0.49 \\
3\end{array}$ \\
\hline \multicolumn{2}{|c|}{$\begin{array}{c}\text { Primary } \\
\text { PSA }\end{array}$} & $\begin{array}{c}11.61 \pm 6.4 \\
5\end{array}$ & $\begin{array}{c}13.41 \pm 6.8 \\
3\end{array}$ & $\begin{array}{c}19.35 \pm 18.0 \\
9\end{array}$ & --- & --- & --- & --- & --- & --- & $\begin{array}{c}0.32 \\
9\end{array}$ \\
\hline \multirow{9}{*}{ 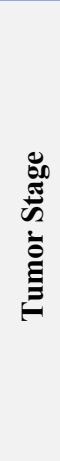 } & PT1a & --- & --- & --- & 0 & 0 & 0 & 0 & 0 & 0 & \multirow{9}{*}{ ণ̊̊ } \\
\hline & PT1b & --- & --- & --- & 0 & 0 & 0 & 0 & 0 & 0 & \\
\hline & PT2a & --- & --- & --- & 1 & 1 & 3 & $14.28 \%$ & $7.69 \%$ & $13.63 \%$ & \\
\hline & PT2b & --- & --- & --- & 0 & 0 & 4 & 0 & 0 & $18.18 \%$ & \\
\hline & PT2c & --- & --- & --- & 4 & 9 & 7 & $57.14 \%$ & $69.23 \%$ & $31.81 \%$ & \\
\hline & PT3a & --- & --- & --- & 0 & 0 & 2 & 0 & 0 & $9.09 \%$ & \\
\hline & PT3b & --- & --- & --- & 1 & 3 & 5 & $14.28 \%$ & $23.07 \%$ & $22.72 \%$ & \\
\hline & PT3c & --- & --- & --- & 1 & 0 & 1 & $14.28 \%$ & 0 & $4.54 \%$ & \\
\hline & Total & --- & --- & --- & 7 & 13 & 22 & $100 \%$ & $100 \%$ & $100 \%$ & \\
\hline \multicolumn{2}{|c|}{$\begin{array}{c}\text { Lymph } \\
\text { node } \\
\text { involvemen } \\
t\end{array}$} & --- & --- & --- & 0 & 0 & 2 & 0 & 0 & $9.09 \%$ & $\begin{array}{c}0.38 \\
5\end{array}$ \\
\hline \multicolumn{2}{|c|}{$\begin{array}{c}\text { Distant } \\
\text { Metastasis }\end{array}$} & --- & --- & --- & 1 & 2 & 0 & $14.28 \%$ & $15.38 \%$ & 0 & $\begin{array}{c}0.16 \\
8\end{array}$ \\
\hline \multirow{5}{*}{ 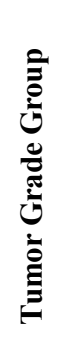 } & 1 & --- & --- & --- & 1 & 1 & 4 & $16.66 \%$ & $16.66 \%$ & $66.66 \%$ & \multirow{5}{*}{$\stackrel{\sim}{\tilde{f}}$} \\
\hline & 2 & --- & --- & --- & 4 & 3 & 15 & $18.18 \%$ & $13.63 \%$ & $68.18 \%$ & \\
\hline & 3 & --- & --- & --- & 2 & 4 & 0 & $33.33 \%$ & $66.66 \%$ & 0 & \\
\hline & 4 & --- & --- & --- & 0 & 3 & 0 & 0 & $100 \%$ & 0 & \\
\hline & 5 & --- & --- & --- & 0 & 2 & 3 & 0 & $40 \%$ & $60 \%$ & \\
\hline
\end{tabular}

*T-test and chi-square test were performed on quantitative and qualitative data, respectively. Mortality was evaluated by Cox proportional Hazard test.

\section{Discussion}

What we investigated in the present study was the association of ERG expression and its intensity with PC. In this study the specificities known as outcomes involve mortality, lymph node invasion, tumor's grade, and metastasis; however, we couldn't find a significant correlation between ERG expression and any of the elements mentioned above, which has been consistent with some of the studies, although there were conflicting results, too.

In Yaskiv et al. study, high grade prostate neoplasia correlated with positive ERG expression and also all the samples negative for PC, were negative for ERG expression too (22). Verdu et al., similar to our study, demonstrated no significant correlation between ERG expression and Gleason score, tumor invasion and lymph node involvement (21). Although Qi et al. used the same methods and couldn't find any correlation of age, disease stage, Gleason score or Ki67 index with ERG expression, but a remarkable association was obtained between ERG expression and preoperative PSA and mortality rate (23). In comparison to our study, $\mathrm{Xu}$ et al. found a significant link between ERG expression and lower age; though, in accordance with our study, Gleason score and disease stage manifested no affinity to ERG expression (24). In Bokhorst et al. survey, ERG expression level was incapable of predicting Gleason score $\geq 7$ as a post-prostatectomy prognostic factor (25). Similar to our results, Pan et al. declared no relevance between ERG expression and age, Gleason score and even PSA; nevertheless, ERG 
expression showed a decreased level in the metastatic cases (26). In the study of Taris et al. in 2014, on cocaine race, ERG expression was associated with higher grades of PC as well as its metastatic form; albeit; this issue was not valid in the African race (11.5\% vs 33\%) (27). In the latest study of Koide et al. in 2019 regarding metastatic prostate cancer, no remarkable correlation was detected between ERG expression and two groups of incidental and metastatic patients (28).

Summary of the alluded investigations suggests diverse and paradoxical results regarding the link between ERG expression and either mortality or PC extension in different societies. In fact, this relation vigorously is under the influence of demographic features, ethnic and genetic factors; therefore, employment of ERG expression in PC outcomes prediction is favorable in some communities and on the other hand, inefficient in others.

In the present study, frequency of ERG expression in PC patients was $41.6 \%$ which has been so close to previous studies concerning this theme. Yaskiv et al. along with Verdu et al. reported the ERG expression rate in their studies as $42 \%$ and $49 \%$, respectively; as it can be noted, the numbers were close to our result (21, 22). In contrast, He et al., Qi et al., Pan et al. and Bismar et al. attained much fewer percentages, like $15.5 \%, 23.2 \%, 15.4 \%$ and $28.2 \%$, respectively $(16,23$, 26, 29). Thus, the preceding studies, in general, displayed ERG expression involves a broad spectrum ranging from $15.4 \%$ to $49 \%$ in different societies, influenced by geographical and ethnic traits.

Our study had some limitations. The study population was small and only included patients from
Sina hospital, one of the main hospitals in Iran and other factors such as patient characteristics or antibody specifications interfered. Further studies including more cases and ancillary tests are necessary for introducing a prognostic factor.

\section{Conclusion}

In a nutshell, in our belief, evaluation of ERG expression and its intensity may have no essential role as an acceptable prognostic factor for anticipating whether prostate cancer itself or the outcomes accompanied in Iranian population.

\section{Author Contributions}

HMT and SMK were the principal investigator, project coordinator, and supervisor, LAS was the pathologist who checked the ERG expression professor who the surgery was under his supervision, AN wrote the manuscript.

\section{Acknowledgements}

Patient consent undertook before surgery based on the ethical code of Tehran University of Medical Sciences Ethics committee. This study was supported by Urology Research Center, Tehran University of Medical Sciences, Tehran, Iran.

\section{Conflict of Interest}

All authors claim that there is no potential competing or conflict of interest.

\section{References}

1. Jemal A, Siegel R, Ward E, Hao Y, Xu J, Murray T, et al. Cancer statistics, 2008. CA Cancer J Clin. 2008;58(2):71-96. [DOI:10.3322/CA.2007.0010] [PMID]

2. Ferlay J, Parkin DM, Steliarova-Foucher E. Estimates of cancer incidence and mortality in Europe in 2008. $\begin{array}{llll}\text { Eur } & \text { J } & \text { Cancer. 2010;46(4):765-81. }\end{array}$ [DOI:10.1016/j.ejca.2009.12.014] [PMID]

3. Wood DE. National Comprehensive Cancer Network (NCCN) Clinical Practice Guidelines for Lung Cancer Screening. Thorac Surg Clin. 2015;25(2):185-97. [DOI:10.1016/j.thorsurg.2014.12.003] [PMID]

4. Brawley OW. Trends in prostate cancer in the United States. J Natl Cancer Inst Monogr. 2012;2012(45):1526. [DOI:10.1093/incimonographs/lgs035] [PMID] [PMCID]

5. Ross LE, Berkowitz Z, Ekwueme DU. Use of the prostate-specific antigen test among US men: findings from the 2005 National Health Interview Survey. Cancer Epidemiology and Prevention Biomarkers. 2008;17(3):636-44. [DOI:10.1158/1055-9965.EPI-072709] [PMID]

6. Furusato B, Tan SH, Young D, Dobi A, Sun C, Mohamed AA, et al. ERG oncoprotein expression in prostate cancer: clonal progression of ERG-positive tumor cells and potential for ERG-based stratification. Prostate Cancer Prostatic Dis. 2010;13(3):228-37. [DOI:10.1038/pcan.2010.23] [PMID] [PMCID]

7. Sirousbakht S, Rezakhaniha B. Effect of colonoscopy on prostate-specific antigen; new words about an old subject. International Journal of Cancer Management. 2018;11(7). [DOI:10.5812/ijcm.68919]

8. Rezakhaniha B, Pour AN, Siroosbakhat S. Effect of cystoscopy on prostate-specific antigen, new words about old subject. Iranian Journal of Cancer Prevention. 2010;3(4). 
9. Denmeade SR, Isaacs JT. A history of prostate cancer treatment. Nat Rev Cancer. 2002;2(5):389-96. [DOI:10.1038/nrc801] [PMID] [PMCID]

10. Feldman BJ, Feldman D. The development of androgen-independent prostate cancer. Nat Rev Cancer. 2001;1(1):34-45. [DOI:10.1038/35094009] [PMID]

11. Petrovics G, Liu A, Shaheduzzaman S, Furusato B, Sun $\mathrm{C}$, Chen Y, et al. Frequent overexpression of ETSrelated gene-1 (ERG1) in prostate cancer transcriptome. Oncogene. 2005;24(23):3847-52. [DOI:10.1038/sj.onc.1208518] [PMID]

12. Kumar-Sinha C, Tomlins SA, Chinnaiyan AM. Recurrent gene fusions in prostate cancer. Nat Rev Cancer. 2008;8(7):497-511. [DOI:10.1038/nrc2402] [PMID] [PMCID]

13. Reddy ES, Rao VN, Papas TS. The erg gene: a human gene related to the ets oncogene. Proc Natl Acad Sci U S A. 1987;84(17):6131-5. [DOI:10.1073/pnas.84.17.6131] [PMID] [PMCID]

14. Rao VN, Papas TS, Reddy ES. erg, a human ets-related gene on chromosome 21: alternative splicing, polyadenylation, and translation. Science. 1987;237(4815):635-9.

[DOI:10.1126/science.3299708] [PMID]

15. Din NU, Qureshi A, Mansoor S. Utility of p63 immunohistochemical stain in differentiating urothelial carcinomas from adenocarcinomas of prostate. Indian Journal of Pathology and Microbiology. 2011;54(1):59. [DOI:10.4103/0377-4929.77326] [PMID]

16. He H, Magi-Galluzzi C, Li J, Carver P, Falzarano S, Smith K, et al. The diagnostic utility of novel immunohistochemical marker ERG in the workup of prostate biopsies with "atypical glands suspicious for cancer". The American journal of surgical pathology. 2011;35(4):608-14. [DOI:10.1097/PAS.0b013e31820bcd2d] [PMID]

17. Lotan TL, Gupta NS, Wang W, Toubaji A, Haffner $\mathrm{MC}$, Chaux A, et al. ERG gene rearrangements are common in prostatic small cell carcinomas. Mod Pathol. 2011;24(6):820-8. [DOI:10.1038/modpathol.2011.7] [PMID] [PMCID]

18. Duterque-Coquillaud M, Niel C, Plaza S, Stehelin D. New human erg isoforms generated by alternative splicing are transcriptional activators. Oncogene. 1993;8(7):1865-73.

19. Miettinen M, Wang Z-F, Paetau A, Tan S-H, Dobi A, Srivastava $\mathrm{S}$, et al. ERG transcription factor as an immunohistochemical marker for vascular endothelial tumors and prostatic carcinoma. The American journal of surgical pathology. 2011;35(3):432-41. [DOI:10.1097/PAS.0b013e318206b67b] [PMID] [PMCID]
20. Leyten GH, Hessels D, Jannink SA, Smit FP, de Jong $\mathrm{H}$, Cornel EB, et al. Prospective multicentre evaluation of PCA3 and TMPRSS2-ERG gene fusions as diagnostic and prognostic urinary biomarkers for prostate cancer. European urology. 2014;65(3):534-42. [DOI:10.1016/j.eururo.2012.11.014] [PMID]

21. Verdu M, Trias I, Roman R, Rodon N, Garcia-Pelaez $\mathrm{B}$, Calvo $\mathrm{M}$, et al. ERG expression and prostatic adenocarcinoma. Virchows Arch. 2013;462(6):639-44. [DOI:10.1007/s00428-013-1415-3] [PMID]

22. Yaskiv O, Zhang X, Simmerman K, Daly T, He H, Falzarano S, et al. The utility of ERG/P63 double immunohistochemical staining in the diagnosis of limited cancer in prostate needle biopsies. Am J Surg Pathol. 2011;35(7):1062-8. [DOI:10.1097/PAS.0b013e318215cc03] [PMID]

23. Qi M, Yang X, Zhang F, Lin T, Sun X, Li Y, et al. ERG rearrangement is associated with prostate cancerrelated death in Chinese prostate cancer patients. PloS one. 2014;9(2):e84959. [DOI:10.1371/journal.pone.0084959] [PMCID]

24. Xu B, Chevarie-Davis M, Chevalier S, Scarlata E, Zeizafoun N, Dragomir A, et al. The prognostic role of ERG immunopositivity in prostatic acinar adenocarcinoma: a study including 454 cases and review of the literature. Hum Pathol. 2014;45(3):48897. [DOI:10.1016/j.humpath.2013.10.012] [PMID]

25. Bokhorst LP, Roobol MJ, Bangma $\mathrm{CH}$, van Leenders GJ. Effect of pathologic revision and Ki67 and ERG immunohistochemistry on predicting radical prostatectomy outcome in men initially on active surveillance. Prostate. 2017;77(10):1137-43. [DOI:10.1002/pros.23372] [PMID]

26. Pan XY, Tan JY, Nie L, Yin XX, Gong J, Chen XQ, et al. [Prognostic Significance of ERG Gene Rearrangement and Protein Expression in Prostate Cancer]. Sichuan Da Xue Xue Bao Yi Xue Ban. 2017;48(1):66-70.

27. Taris M, Irani J, Blanchet $\mathrm{P}$, Multigner L, Cathelineau $\mathrm{X}$, Fromont G. ERG expression in prostate cancer: the prognostic paradox. Prostate. 2014;74(15):1481-7. [DOI:10.1002/pros.22863] [PMID]

28. Koide $\mathrm{H}$, Kimura $\mathrm{T}$, Inaba $\mathrm{H}$, Sato $\mathrm{S}$, Iwatani $\mathrm{K}$, Yorozu T, et al. Comparison of ERG and SPINK1 expression among incidental and metastatic prostate cancer in Japanese men. The Prostate. 2019;79(1):3-8. [DOI:10.1002/pros.23705] [PMID]

29. Bismar TA, Hegazy S, Feng Z, Yu D, Donnelly B, Palanisamy N, et al. Clinical utility of assessing PTEN and ERG protein expression in prostate cancer patients: a proposed method for risk stratification. J Cancer Res Clin Oncol. 2018;144(11):2117-25. [DOI:10.1007/s00432-018-2730-5] [PMID] 